\title{
Human Embryonic Stem Cells in Treatment of Spinal Cord Injury: A Prospective Study
}

\author{
Geeta Shroff ${ }^{\mathrm{a}, \mathrm{c}}$, Puneet Agarwal ${ }^{\mathrm{b}}$, Avinash Mishra ${ }^{\mathrm{a}}$, Nayan Sonowal ${ }^{\mathrm{a}}$
}

\begin{abstract}
Background: Spinal cord injury (SCI) is a devastating disease which impacts the patient physically, psychologically and financially. Although the pharmacological and non-pharmacological methods are used, none of them are able to improve the quality of life permanently. Recent advancement in the regenerative medicines has risen a new dawn for treatment of SCI.
\end{abstract}

Method: In the current study, human embryonic stem cells (hESCs) were used on pre-diagnosed chronic SCI patients with informed written and video consent. The cell lines were cultured and maintained in a good manufacturing practice (GMP), good laboratory practice (GLP), and good tissue practice (GTP) compliance laboratory which were free of animal product and chromosomally stable. The patients were scored according to the American Spinal Injury Association (ASIA) scale. There were four treatment phases (T1, T2, T3 and T4) with gap phases. Patient received $0.25 \mathrm{~mL}$ of hESCs through intramuscular (IM) route twice daily, $1 \mathrm{~mL}$ of hESCs every 10 days through intravenous (IV) route and $1-5 \mathrm{~mL}$ of hESCs for 5 - 7 days through supplemental routes. Magnetic resonance imaging (MRI) tractography was performed for all the patients before and after the therapy.

Result: Of 11 patients at the beginning of therapy, seven patients were on ASIA score A, one patient was on ASIA score B, two patients were on ASIA score $\mathrm{C}$ and one patient was on ASIA score D. At the end of treatment, three patients moved to lower scale, i.e. ASIA score $\mathrm{D}$, two patients to ASIA score $\mathrm{C}$ and rest all the patients were on ASIA score A. There was a remarkable improvement in the signs and symptoms of patients clinically. No adverse event and teratoma formation was observed.

Conclusion: hESC therapy showed remarkable improvement in the clinical symptoms in SCI patients.

Manuscript accepted for publication June 25, 2015

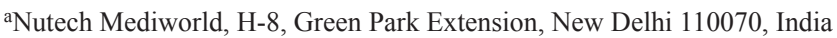
${ }^{b}$ Max Super Speciality Hospital, Press Enclave Marg, Saket, New Delhi, India ${ }^{c}$ Corresponding Author: Geeta Shroff, Nutech Mediworld, H-8, Green Park Extension, New Delhi 110070, India. Email: geetashroff@hotmail.com

doi: http://dx.doi.org/10.14740/jnr339w
Keywords: Spinal cord injury; Human embryonic stem cells; ASIA score; Prospective study

\section{Introduction}

Spinal cord injury (SCI) not only impacts the physical, psychological, and social life of patient, but also makes a significant impact financially. Approximately, 250,000 to 500,000 people suffer with SCI globally every year [1]. In India, the prevalence of SCI is between $1.85 \%$ and $2.19 \%$ [2]. According to the international standards set forth by the American Spinal Injury Association (ASIA), the severity of an injury is categorized as either complete or incomplete. A complete injury is defined as the absence of sensory and motor function in the lowest sacral segments. If there is some preserved motor and sensory function below the level of injury, the case is diagnosed as incomplete motor and sensory SCI [3, 4].

There have been several strategies to enhance neurological recovery like surgical intervention, physiotherapy, and pharmacological interventions but none of these have proven to be effective. Generally, high dose of corticosteroids like methylprednisolon is used for acute conditions [5]. Latest advancements in regenerative medicines and neuroscience have attracted various researchers towards the novel technologies for treating SCI. Ronsyn et al stated that for re-establishing the connection between central nervous system (CNS) and peripheral nervous system (PNS) replacement of neurons and oligodendrocytes will be the key elements [6]. Stem cell transplantation is a promising technology that has the potential to replace damaged neurons, re-establish lost axonal connections, provide neuroprotection and improve the functional recovery after SCI $[7,8]$. A review by Lee et al explained that human embryonic stem cells (hESCs) have a huge potential for differentiation and can provide neuronal or glial cells for transplantation [9]. Over the past decade, use of embryonic stem cells in animal models of SCI has demonstrated beneficial effects $[10,11]$.

The present prospective study evaluated the safety and efficacy of hESC in patients with SCI. We have previously demonstrated the safety and efficacy of hESC therapy in patients with cerebral palsy [12], cortico-visual impairment [13] and Friedrich ataxia [14]. We have also reported some patients who 

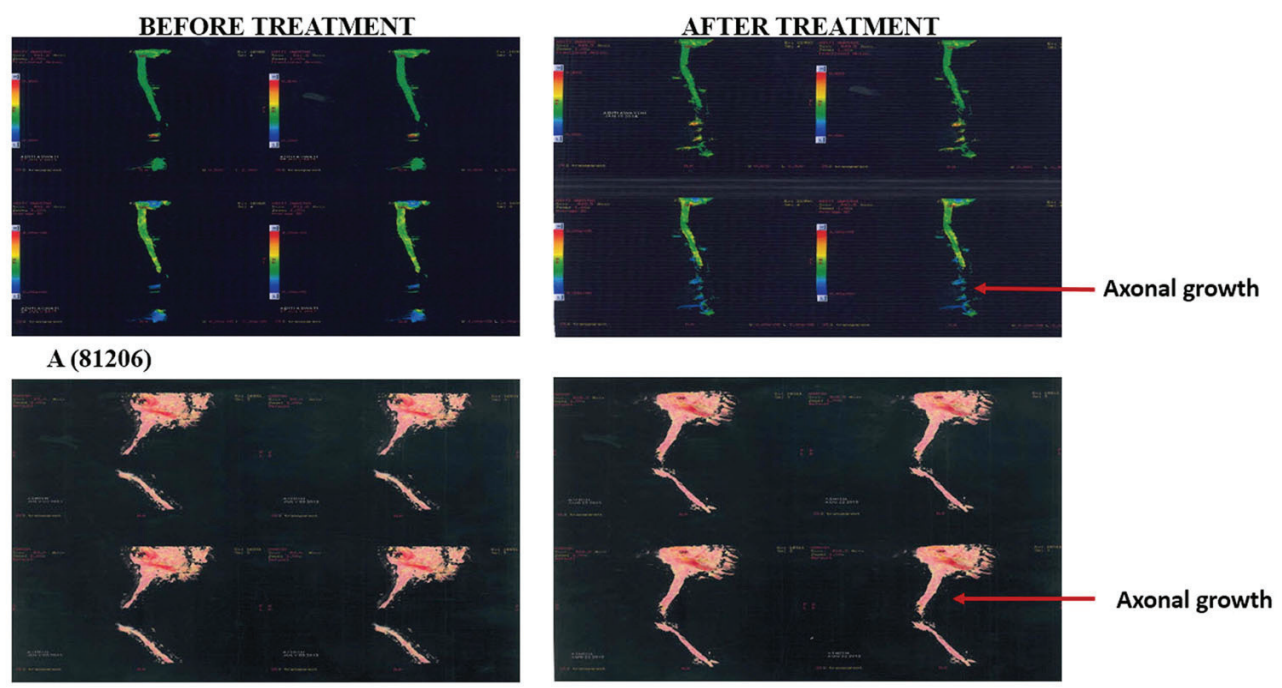

B (81215)
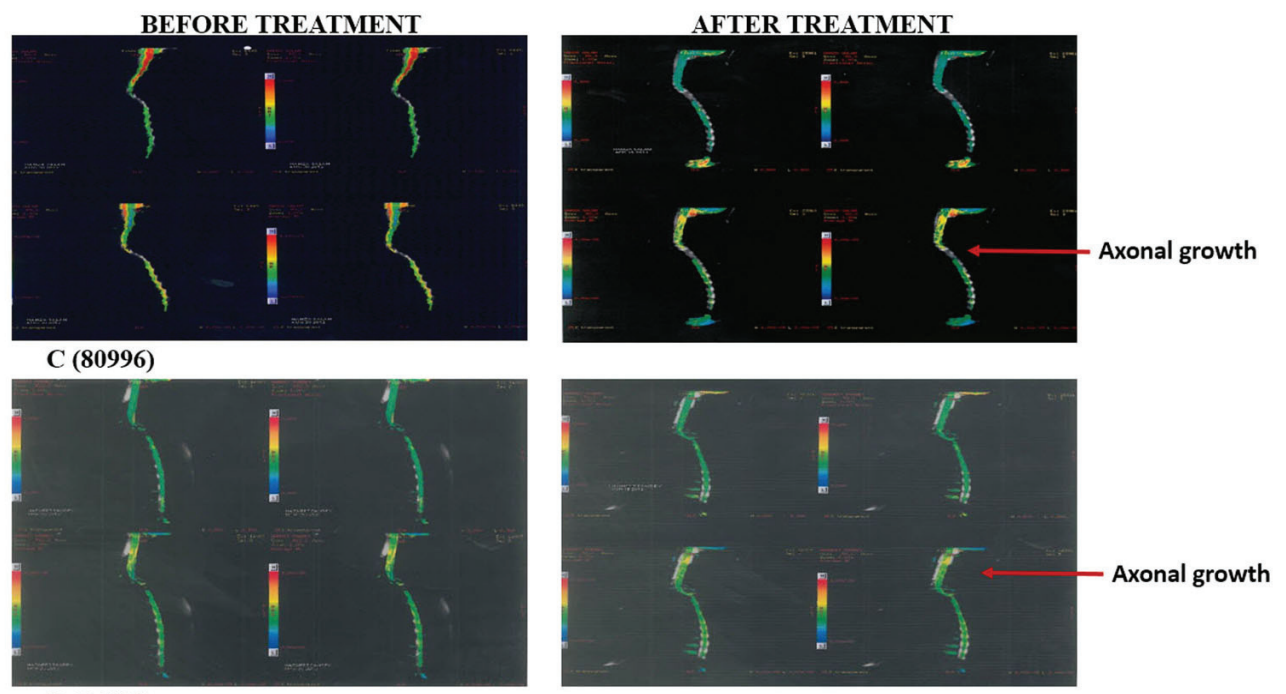

D (81190)

Figure 1. Tractography images of patients before and after hESC therapy.

benefitted with our hESC therapy [15].

\section{Method}

\section{Cell culture and differentiation}

The cells are cultured and maintained as per our patented technology (United States Granted Patent No. US 8592,208,52) in a good manufacturing practice (GMP), good laboratory practice (GLP), and good tissue practice (GTP) compliant laboratory. The cell lines are free of animal product and are chromosomally stable. The detailed procedure of cell culture and differentiation was elaborated previously [16]. The safety and efficacy of these cells has been established in patients with incurable conditions [17].

\section{Study population}

Thoroughly diagnosed patients with chronic SCI who were on traditional therapies like physiotherapy and occupational therapy were included in the study. Pregnant, lactating patients and patients who were confirmed to receive other forms of cell therapies were excluded from the treatment. A written and video consent from each patient was taken before initiation of the treatment. The whole treatment was supervised by the team of external consultants. An external clinical research organization (CRO) validated the whole process. The patients were scored 

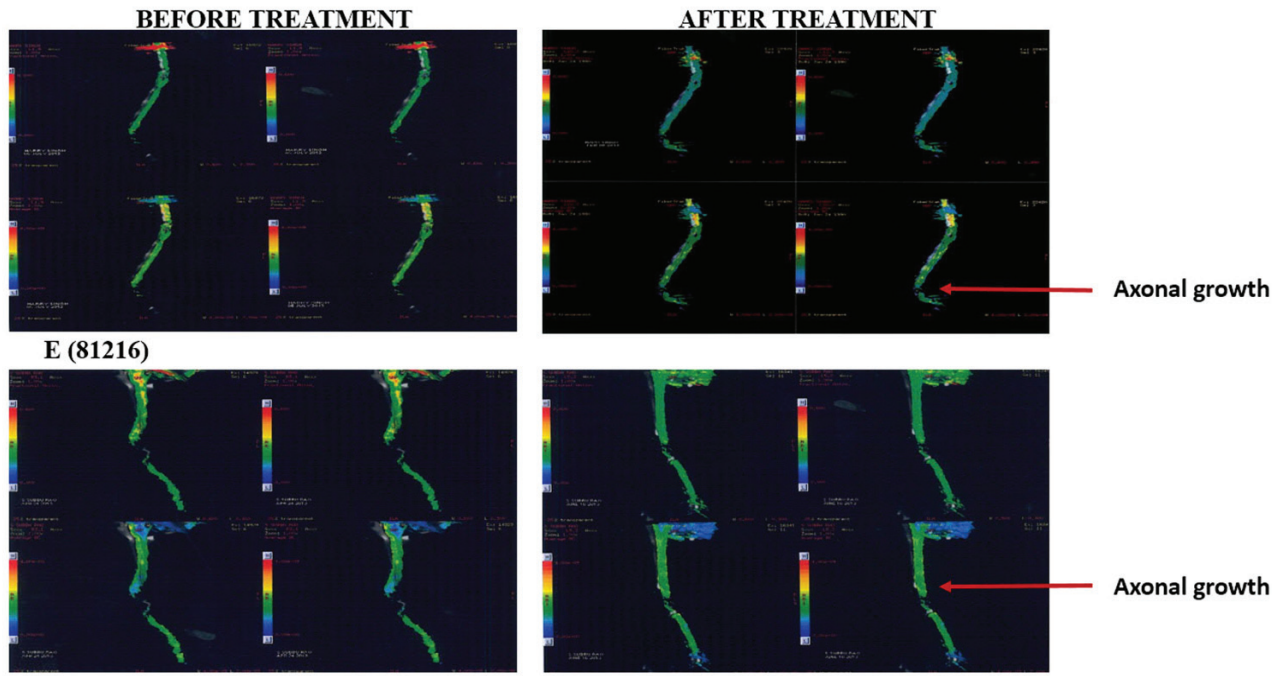

F (81193)
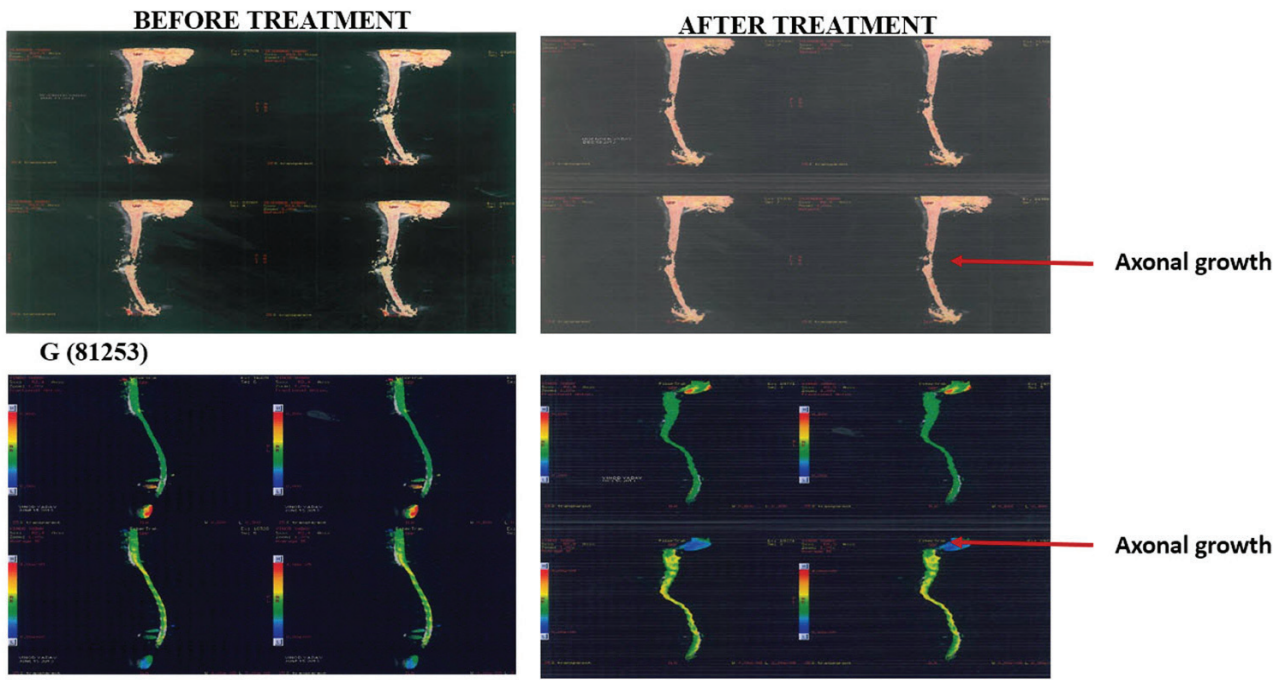

H (81195)

Figure 1. Tractography images of patients before and after hESC therapy. - (continued)

as per ASIA scale by independent physicians before and after the treatment and by the in house doctors and the rehabilitation team. The magnetic resonance imaging (MRI) tractography of patients was done before and after the treatment (Fig. 1).

\section{Study design}

The data of patients with SCI treated with hESC at a single site in New Delhi, India were collected prospectively. The study protocol was approved by an Institutional Independent Ethics Committee (IEC) for stem cell research and therapy of our institute that reports to the National Apex Committee for Stem Cell Research and Therapy (NAC-SCRT).

SCI was defined as damage to any part of the spinal cord
( $>3$ months) that resulted in a change, either temporary or permanent, in the cord's normal motor, sensory, or autonomic function. The patients had to undergo a detailed examination by the doctors and the rehabilitation team before, during, and after each treatment cycle. MRI, tractography and biochemical investigations were done for all the patients before the start of the treatment and then at regular intervals. A separate team of doctors (not involved with patient care) examined the observations documented by the various teams and further graded the patients.

After diagnosis and procedural details, $0.05 \mathrm{~mL}$ of $\mathrm{hESC}$ was injected to the patients subcutaneously (SC) to test the hypersensitivity reactions. The study comprised of our treatment phases with gap phases in between. The patients entered the first treatment phase (T1, 8 weeks for paraplegics and 12 
Table 1. Details of ASIA Score During the Treatment Phases and Duration of Treatment and Gap Phases

\begin{tabular}{|c|c|c|c|c|c|c|c|c|c|c|}
\hline \multirow{3}{*}{ Patient No. } & \multicolumn{8}{|c|}{ ASIA score } & \multirow{3}{*}{ Treatment days } & \multirow{3}{*}{ GAP phase days } \\
\hline & \multicolumn{2}{|c|}{ T1 } & \multicolumn{2}{|c|}{ T2 } & \multicolumn{2}{|c|}{ T3 } & \multicolumn{2}{|c|}{ T4 } & & \\
\hline & Start & End & Start & End & Start & End & Start & End & & \\
\hline 80996 & A & A & B & $\mathrm{C}$ & $\mathrm{D}$ & $\mathrm{D}$ & $\mathrm{D}$ & $\mathrm{D}$ & 215 & 207 \\
\hline 81191 & $\mathrm{C}$ & $\mathrm{C}$ & $\mathrm{C}$ & $\mathrm{C}$ & $\mathrm{D}$ & $\mathrm{D}$ & & & 127 & 206 \\
\hline 81192 & A & A & & & & & & & 54 & 0 \\
\hline 81193 & $\mathrm{C}$ & $\mathrm{C}$ & $\mathrm{C}$ & $\mathrm{C}$ & & & & & 98 & 93 \\
\hline 81194 & B & B & $\mathrm{C}$ & $\mathrm{C}$ & & & & & 77 & 85 \\
\hline 81196 & A & A & & & & & & & 17 & 0 \\
\hline 81206 & A & A & A & A & A & A & & & 421 & 170 \\
\hline 81215 & A & A & & & & & & & 42 & 0 \\
\hline 81216 & A & A & A & A & A & A & & & 111 & 320 \\
\hline 81223 & A & A & A & A & A & A & & & 190 & 298 \\
\hline 81253 & $\mathrm{~B}$ & $\mathrm{~B}$ & $\mathrm{C}$ & $\mathrm{C}$ & $\mathrm{C}$ & $\mathrm{C}$ & & & 121 & 167 \\
\hline
\end{tabular}

weeks for quadriplegics) after the hypersensitivity testing. During T1, $0.25 \mathrm{~mL}(<4$ million cells) of hESC was injected to patients through intramuscular (IM) route twice daily to "prime" body and let the patient's immune system to accept the stem cells. About $1 \mathrm{~mL}$ of hESCs $(<16$ million cells) was injected to patients through intravenous (IV) route for every 10 days to "home in" the required area. For local action, $1-5 \mathrm{~mL}$ of hESCs was injected to the patients every $5-7$ days through any of the supplemental routes (epidural infusion or injection/ caudal injection, $5 \mathrm{~mL}$ subarachnoid injection $2 \mathrm{~mL}$ and deep spinal injection $1 \mathrm{~mL}$ ). As the quadriplegic patients take more time to recover, the treatment and gap phase duration were varied for paraplegic and quadriplegic patients.

The patients entered into the next treatment phases (T2, T3 and T4) after the gap period of $4-8$ months. The patients followed the same dosage regime as that of T1. The duration for each treatment phase was 4 - 6 weeks with 4 - 8 months of gap phase. Extra doses of hESCs were injected to the patients through the supplemental routes during the T2, T3 and $\mathrm{T} 4$ phases. The patients received no steroids and immunosuppressants during the treatment.

\section{Results}

\section{Patients}

Overall, 11 patients (seven paraplegics and four quadriplegics) were enrolled. The mean age of the patients was 27 years. The average treatment days of hESC therapy were 149 days. The days of treatment in T1 were 73 days for quadriplegic patients and 62 days for paraplegic patients and the average gap period was 122 days for quadriplegic patients and 136 days for paraplegic patients. The duration of treatment phases and gap phases for all the patients is listed in Table 1 .

\section{Change in ASIA impairment scale from admission to discharge}

\section{Treatment phase 1}

Of the patients who entered the T1, seven had ASIA score A, two had ASIA score B and two had ASIA score C. At the end of T1, three patients discontinued the treatment. No change in the ASIA score was observed at the end of the T1. After the gap phase, three patients were on ASIA score A, one patient was on ASIA score B and four patients were on ASIA score C (Table 1).

\section{Treatment phases 2, 3 and 4}

After the gap phase, eight patients entered the T2 phase. The process of dosing was same as that for T1. Subsequent to the T2 phase, only one patient moved from ASIA score B to ASIA score C. During the gap phase between T2 and T3, two patients moved from ASIA score C to ASIA score D. Thus, at the end of T2, three patients had ASIA score A, and five patients had ASIA score C.

In treatment phase $\mathrm{T} 3$, only six patients continued the treatment. Of these, three had ASIA score A, one had ASIA score $\mathrm{C}$ and two had ASIA score D. There was no change in their ASIA score after the end of T3.

After the gap phase, only one patient enrolled for treatment phase T4. The patient was on ASIA score D. At the end of T4, the ASIA score of patient remained same (Table 1).

Overall, seven patients were on ASIA score A, two patients were on ASIA score B and two patients were on ASIA score $\mathrm{C}$ at the beginning of treatment. At the end of treatment, two patients moved to lower scale, i.e. ASIA score D, two patients to ASIA score $\mathrm{C}$ and rest all the patients were on ASIA 
Table 2. Radiological Examinations of Patients Before and After the Treatment

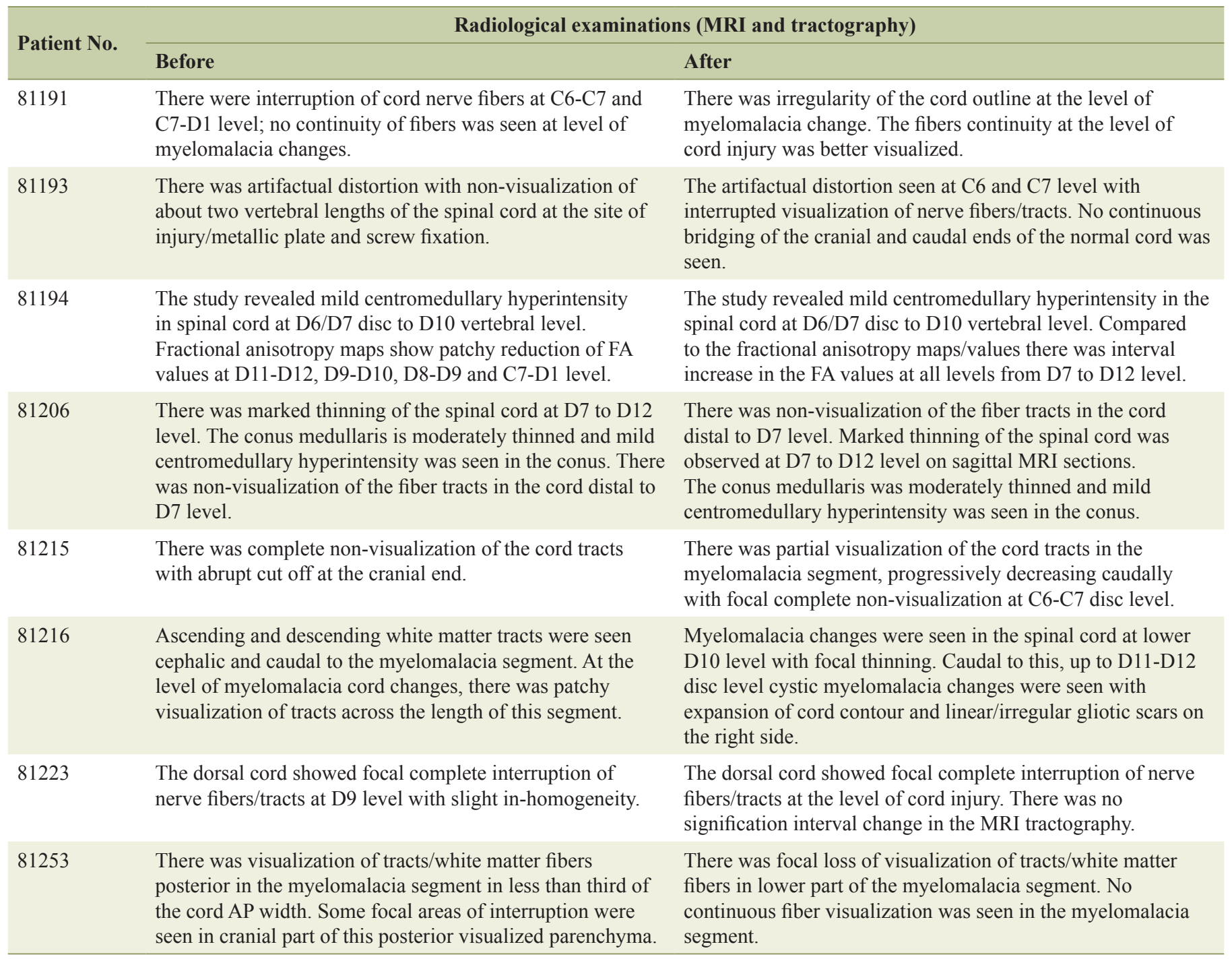

score A.

\section{Radiological examinations}

The radiological examinations for all the patients were done before and after the treatment (Fig. 1, Table 2). Improvements in patients were not clearly understood through the radiological examinations, but the patients showed remarkable improvement in clinical signs and symptoms (Table 3 ).

\section{Safety evaluation}

There were no death or adverse events observed during the study period. None of the patients reported teratomas formation during or after the study. No immune reactions were observed. None of our patients were given immunosuppressants.

\section{Discussion}

The standard treatment for chronic SCI includes high dose of steroids (methylprednisolone) and immunosuppressants. The mild therapeutic effect of methylprednisolone is associated with number of other side effects $[5,18]$. Hugenholtz stated that there are no evidence-based standards for the use of high dose of methylprednisolone for the treatment of SCI [19]. The surgical treatment for SCI patients does not show any improvement between treated and non-treated patients [20]. Thus, very few or negligible treatment options are available for patients with SCI. Recently, cell-based therapies have shown some hope for patients with SCI.

The treatment strategy for patients with SCI includes replacement of damaged neural tissues and re-establishing connections between the CNS and PNS [6]. Thus, self-renewal and differentiation into multiple cells types would be best suited for patients with SCI. hESCs are able to replicate in- 
Table 3. Clinical Status of Patients Before and After the Treatment

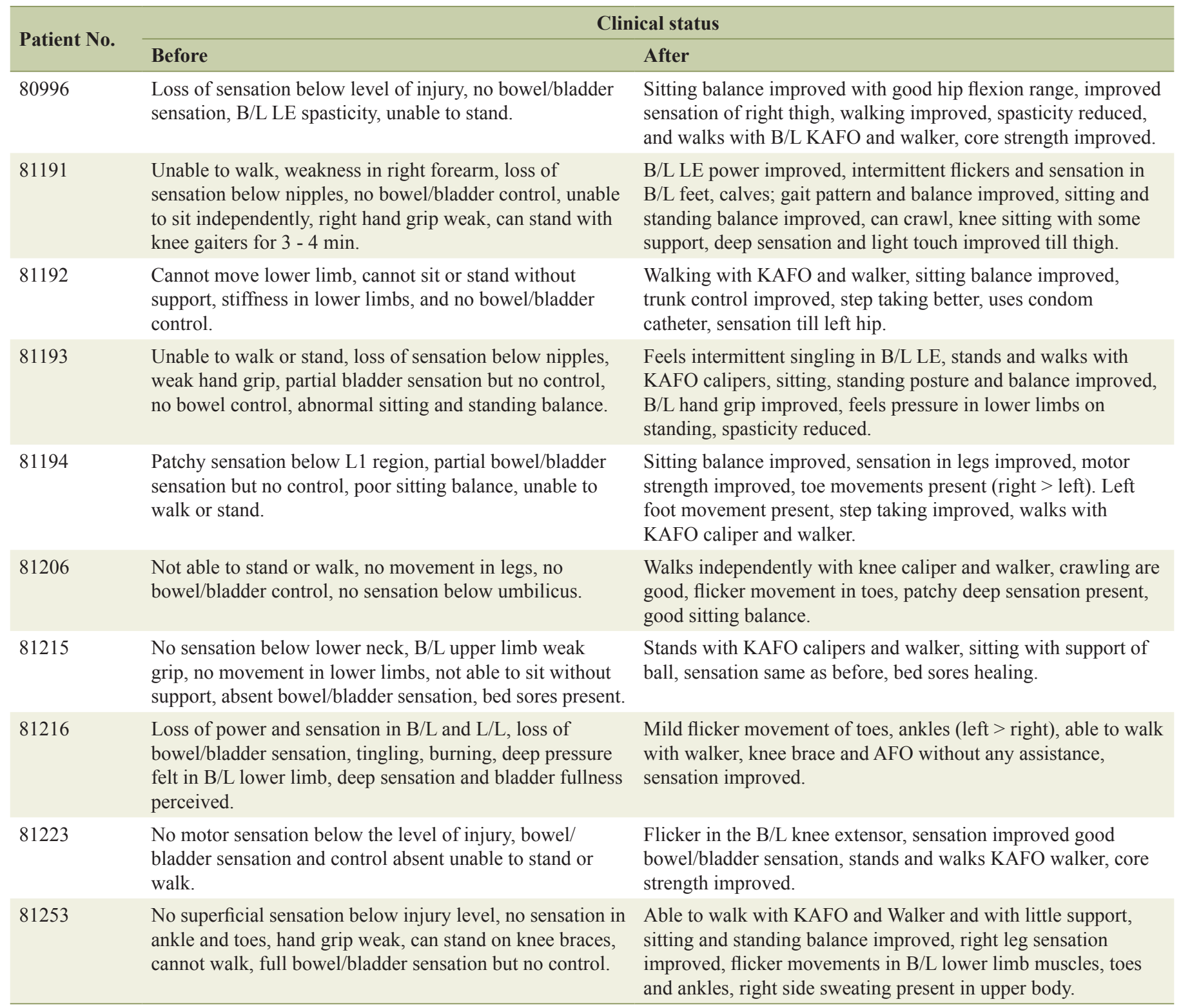

KAFO: knee-ankle-foot orthosis; AFO: ankle-foot orthosis; LE: lower extremity; B/L: bilateral.

definitely, differentiate into all three primary germ layers cell lines and are karyotypically stable [7]. During the past decade, a number of studies were conducted in animal models to observe the capabilities of stem cells in improving the motor functions in patients with SCI. Li et al transplanted the placenta-derived mesenchymal stem cells (PDMSCs) to rat models of SCI. They observed a significant improvement in the motor and hind limb functions after 3 weeks of study. The Basso, Beattie, and Bresnahan scale (BBB) also shifted from 2 to 13 within the 3 weeks of treatment [21]. Kerr et al studied the human pluripotent stem cell (hPSC) derivatives transplanted to rat models to observe the improvement in the motor functions. The author observed significant improvement in the hind limb locomotion as compared with controlled animals in 12 weeks of study [22].

Sharp et al used hESC-derived oligodendrocyte progenitors (OPCs) in the adult cervical contusion rat models. The authors observed that the transplanted hESC-derived OPCs survived even after the 9 weeks of study period [23]. Rossi et al observed that the transplanted animals had an improved functional outcome with an early recovery rate of balance and coordination and skilled forelimb movement when human motor neuron progenitor ( $\mathrm{hMNP}$ ) cells derived from hESCs were transplanted in rats with SCI [24]. Besides, the evaluation of stem cells over the animal models, some early phase clinical trials was performed to check the efficacy of stem cells in SCI which yielded mixed results. Yoon et al conducted a non-randomized phase I/II clinical trial to treat SCI with transplantation 
of bone marrow cells. They observed a significant change in the ASIA score of the patients in acute and sub-acute treatment group. No improvement was observed in patients of chronic treatment group [25]. Mackay-Sim et al conducted a 3-year clinical trial in 12 paraplegic patients. They transplanted the olfactory ensheathing cells (OECs) through multiple routes. They found no changes in the ASIA score after 3 years. There was no improvement in the neurological and functional level of any patient [26]. Lima et al performed a pilot scale clinical study in seven patients of chronic SCI. They transplanted the OEC to the SCI patients through surgical mode. The authors found significant changes in the MRI observations and ASIA score. The bowel and bladder movement of patients were also improved [27].

We have previously reported improvement in some of our patients with SCI after undergoing hESC therapy [15]. In another study, we have reported improvement in bowel and bladder sensation and control in our patients with SCI [28]. We did not include patients with acute SCI in our study to rule out the natural recovery of disease. All our patients had SCI for more than 3 months and had not benefitted from any other treatment. Previously, Bretzner and his colleagues have also stated that chronic SCI patients are more acceptable patients for hESC-derived transplantations as compared to acute SCI patients. These patients are "less likely to suffer opportunity costs from study participation" which is an important ethical consideration when "knowledge value", not "therapeutic benefit", motivates the research [29]. Our study included treatment phases (T1, T2, T3 and T4) separated by gap periods in between. From our prior experience with hESCs, we observed that treatment period of $>8$ weeks for paraplegic patients and $>12$ weeks for quadriplegic patients did not yield any better results. All organs develop within 14 - 16 weeks of gestation during embryonic development in humans [30]. On this basis, a gap phase of 4 - 6 months was included between out treatment periods to allow hESCs to grow, repair and regenerate the affected area.

Studies have suggested that mesenchymal stem cells (MSCs) have the homing capability because of their therapeutic effect at the injured or inflamed tissue. The role of chemokines, growth factors, cytokines, transforming growth factors (TGF)- $\beta 1$, and tumor necrosis factors (TNF)- $\alpha$ regulated the migration of MSCs to the injured tissue. They induce the upregulation of selectins and activate the integrins present on the stem cells [31]. Melief et al suggested the probable mechanism of action of MSCs. According to them, the effect of MSCs may be observed by the regulatory T cells. MSCs release the TGF- $\beta$, which serve as a growth factor for the regulatory $\mathrm{T}$ cells. The regulatory $\mathrm{T}$ cells increase the levels of IL2, IL10, CCL18 and prostaglandin E2 via different pathways and play an important role in reconciling inflammation and tissue repair [32]. In our patients with SCI, the hESCs could have followed the same route from site of injection to the site of action and helped in regeneration of the injured tissue. However, re-establishing the lost axonal connections after recovery takes more time and the new tissues have to gain their functionality. We also used supplemental routes to administer SCI to augment recovery as proximity to the injured site helps in faster migration and recovery. Previously, Eggenhfer et al have shown that the route through which MSCs were administered, influenced their potential to migrate and home at the site of injury [33]. Further, our hESCs are very small in $0.5-2 \mu \mathrm{m}$ and thus could easily penetrate the body tissues and aid in recovery.

We did not observe any serious adverse event after the hESC therapy. No immunosuppressants were given to our patients. Our patients showed remarkable clinical recovery and the improvements were also evident in the radiological reports after the therapy. However, our study is limited by a small sample size.

\section{Conclusion}

In conclusion, hESC transplantation in patients with SCI is safe and effective and helps improve the clinical condition of the patients. hESC therapy may present a significant advancement in the treatment and rehabilitation of patients with SCI. Future, clinical studies are needed to fully clarify the role and benefit of hESC therapy in patients with SCI.

\section{Conflict of Interest}

The authors have no conflict of interest.

\section{References}

1. International perspectives on spinal cord injury: World Health Organization. Available from http:/www.who.int/ disabilities/policies/spinal_cord_injury/report/en/; Accessed on 13 February, $20 \overline{1} 5$.

2. Anonymous. Spinal Cord Injuries. Rehabilitation Council of India. Available from www.rehabcouncil.nic.in/writereaddata/spinal.pdf/; Accessed on 27 February, 2015.

3. Grossman RG, Frankowski RF, Burau KD, Toups EG, Crommett JW, Johnson MM, Fehlings MG, et al. Incidence and severity of acute complications after spinal cord injury. J Neurosurg Spine. 2012;17(1 Suppl):119-128.

4. Dalbayrak S, Yaman O, Yilmaz T. Current and future surgery strategies for spinal cord injuries. World J Orthop. 2015;6(1):34-41.

5. Bracken MB. Steroids for acute spinal cord injury. Cochrane Database Syst Rev. 2012;1:CD001046.

6. Ronsyn MW, Berneman ZN, Van Tendeloo VF, Jorens PG, Ponsaerts P. Can cell therapy heal a spinal cord injury? Spinal Cord. 2008;46(8):532-539.

7. Erceg S, Lainez S, Ronaghi M, Stojkovic P, Perez-Arago MA, Moreno-Manzano V, Moreno-Palanques R, et al. Differentiation of human embryonic stem cells to regional specific neural precursors in chemically defined medium conditions. PLoS One. 2008;3(5):e2122.

8. Cui YF, Xu JC, Hargus G, Jakovcevski I, Schachner M, Bernreuther C. Embryonic stem cell-derived L1 overexpressing neural aggregates enhance recovery after spinal cord injury in mice. PLoS One. 2011;6(3):e17126.

9. Lee H, Shamy GA, Elkabetz Y, Schofield CM, Harrsion NL, Panagiotakos G, Socci ND, et al. Directed differ- 
entiation and transplantation of human embryonic stem cell-derived motoneurons. Stem Cells. 2007;25(8):19311939.

10. Roy NS, Nakano T, Keyoung HM, Windrem M, Rashbaum WK, Alonso ML, Kang J, et al. Telomerase immortalization of neuronally restricted progenitor cells derived from the human fetal spinal cord. Nat Biotechnol. 2004;22(3):297-305.

11. McDonald JW, Liu XZ, Qu Y, Liu S, Mickey SK, Turetsky D, Gottlieb DI, et al. Transplanted embryonic stem cells survive, differentiate and promote recovery in injured rat spinal cord. Nat Med. 1999;5(12):1410-1412.

12. Shroff G, Gupta A, Barthakur JK. Therapeutic potential of human embryonic stem cell transplantation in patients with cerebral palsy. J Transl Med. 2014;12(1):318.

13. Shroff G, Das L. Human Embryonic Stem Cell Therapy in Cerebral Palsy Children with Cortical Visual Impairment: A Case Series of 40 Patients. J Cell Sci Ther. 2014;5(6):1.

14. Shroff G. A novel approach of human embryonic stem cells therapy in treatment of Friedrich's Ataxia. Int J Case Rep Images. 2015;6:261-266.

15. Shroff G, Gupta R. Human Embryonic Stem Cells in the Treatment of Patients with Spinal Cord Injury. Annals of Neurosciences. 2015;22(4).

16. Shroff G. Establishment and Characterization of a Neuronal Cell line derived from a 2-cell Stage Human Embryo: Clinically Tested Cell-based Therapy for Neurological Disorders. . International Journal of Recent Scientific Research 2015;6(4):3730-3738.

17. Shroff G, Barthakur JK. Safety of Human Embryonic Stem Cells in Patients with Terminal Conditions. Annals of Neurosciences. 2015;22(3).

18. Bracken MB, Shepard MJ, Collins WF, Holford TR, Young W, Baskin DS, Eisenberg HM, et al. A randomized, controlled trial of methylprednisolone or naloxone in the treatment of acute spinal-cord injury. Results of the Second National Acute Spinal Cord Injury Study. N Engl J Med. 1990;322(20):1405-1411.

19. Hugenholtz H. Methylprednisolone for acute spinal cord injury: not a standard of care. CMAJ. 2003;168(9):11451146.

20. Vaccaro AR, Daugherty RJ, Sheehan TP, Dante SJ, Cotler JM, Balderston RA, Herbison GJ, et al. Neurologic outcome of early versus late surgery for cervical spinal cord injury. Spine (Phila Pa 1976). 1997;22(22):2609-2613.

21. Li Z, Zhao W, Liu W, Zhou Y, Jia J, Yang L. Transplantation of placenta-derived mesenchymal stem cell-induced neural stem cells to treat spinal cord injury. Neural Regen Res. 2014;9(24):2197-2204.

22. Kerr DA, Llado J, Shamblott MJ, Maragakis NJ, Irani DN, Crawford TO, Krishnan C, et al. Human embryonic germ cell derivatives facilitate motor recovery of rats with diffuse motor neuron injury. J Neurosci. 2003;23(12):51315140 .

23. Sharp J, Frame J, Siegenthaler M, Nistor G, Keirstead HS. Human embryonic stem cell-derived oligodendrocyte progenitor cell transplants improve recovery after cervical spinal cord injury. Stem Cells. 2010;28(1):152163.

24. Rossi SL, Nistor G, Wyatt T, Yin HZ, Poole AJ, Weiss JH, Gardener MJ, et al. Histological and functional benefit following transplantation of motor neuron progenitors to the injured rat spinal cord. PLoS One. 2010;5(7):e11852.

25. Yoon SH, Shim YS, Park YH, Chung JK, Nam JH, Kim $\mathrm{MO}$, Park HC, et al. Complete spinal cord injury treatment using autologous bone marrow cell transplantation and bone marrow stimulation with granulocyte macrophagecolony stimulating factor: Phase I/II clinical trial. Stem Cells. 2007;25(8):2066-2073.

26. Mackay-Sim A, Feron F, Cochrane J, Bassingthwaighte L, Bayliss C, Davies W, Fronek P, et al. Autologous olfactory ensheathing cell transplantation in human paraplegia: a 3-year clinical trial. Brain. 2008;131(Pt 9):2376-2386.

27. Lima C, Pratas-Vital J, Escada P, Hasse-Ferreira A, Capucho C, Peduzzi JD. Olfactory mucosa autografts in human spinal cord injury: a pilot clinical study. J Spinal Cord Med. 2006;29(3):191-203; discussion 204-196.

28. Shroff G. Bowel/Bladder Sensation and Control in Patients with Spinal Cord Injury Treated with Human Embryonic Stem Cell therapy. ASGCT 18th Annual Meeting. New Orleans, Los Angeles, USA2015.

29. Bretzner F, Gilbert F, Baylis F, Brownstone RM. Target populations for first-in-human embryonic stem cell research in spinal cord injury. Cell Stem Cell. 2011;8(5):468-475.

30. Maahs DM, Siwy J, Argiles A, Cerna M, Delles C, Dominiczak AF, Gayrard N, et al. Urinary collagen fragments are significantly altered in diabetes: a link to pathophysiology. PLoS One. 2010;5(9).

31. Kang SK, Shin IS, Ko MS, Jo JY, Ra JC. Journey of mesenchymal stem cells for homing: strategies to enhance efficacy and safety of stem cell therapy. Stem Cells Int. 2012;2012:342968.

32. Melief SM, Schrama E, Brugman MH, Tiemessen MM, Hoogduijn MJ, Fibbe WE, Roelofs H. Multipotent stromal cells induce human regulatory $T$ cells through a novel pathway involving skewing of monocytes toward anti-inflammatory macrophages. Stem Cells. 2013;31(9):19801991.

33. Eggenhofer E, Luk F, Dahlke MH, Hoogduijn MJ. The life and fate of mesenchymal stem cells. Front Immunol. 2014;5:148. 